Int. J. Odontostomat., 9(1):107-111, 2015.

\title{
Photoelastic Analysis of Two Maxillary Protocols Using Zygomatic Implants
}

\author{
Análisis Fotoelástico de Dos Protocolos Maxilares con Uso de Implantes Cigomáticos
}

\author{
Paulo Hemerson de Moraes***; Mauro de Arruda Nóbilo ${ }^{* * *}$ \\ Márcio de Moraes*; Sergio Olate ${ }^{\star *+* * *+* * *}$ \& José Ricardo de Albergaria Barbosa*
}

DE MORAES, P. H.; NÓBILO, M. A.; DE MORAES, M.; OLATE, S. \& ALBERGARIA-BARBOSA, J. R. Photoelastic analysis of two maxillary protocols using zygomatic implants. Int. J. Odontostomat., 9(1):107-111, 2015.

ABSTRACT: The aim of this study was to analyse the in vitro the stress distribution in craniofacial structures around zygomatic implants. Synthetic polyurethane skulls replicas were used as templates for installation of standard and zygomatic implants performing two techniques using rehabilitation with using one zygomatic implant in the right and left side in combination with 2 and 4 standard implants in the anterior maxilla (group 1 and group 2). The skull replicas of photoelastic resin were subjected to photoelastic analysis after linear loading using an Instron 4411 servohydraulic mechanical testing, with a 2 mm displacement. The stress distribution showed the fringes with concentration in the body and the frontal process of zygomatic bone. In the case of model 1, higher concentrations of stress were found around the standard and zygomatic implants and surrounding bone. Under this condition, the rehabilitation with 2 zygomatics implants and 4 standard implants (group 2) provided the most favorable behavior.

KEY WORDS: photoelastic analysis, maxillary atrophy, zygomatic implants.

\section{INTRODUCTION}

In many patientes, standard implant treatment cannot be performed in the edentulous maxilla because of extensive bone resorption and the presence of extensive maxillary sinuses. Patients with extreme resorption of the maxilla, or defects after tumor resection are complex problems for oral rehabilitation. In the treatment of these patients, bone grafts have been used to reestablish osseous contours providing possibilities for a tooth anchorage system. The maxillary autogenous graft are demanding for the patients and usually require hospitalization (Aparicio et al., 2008; Aghabeiji \& Bousdras, 2007).

Introducing the zygoma implant concept, Brånemark presented a nongrafting alternative for the treatment of this group of patients (Ujigawa et al., 2007). Treatment with zygoma implant does not require hospitalization and usually allows the patients to use their maxillary dentures immediately after surgery. In general, zygomatic fixtures can be used in patients with totally and partially edentulous maxillary which have insufficient bone volume for placement of regular implants. The zygomatic implants with standard implants in the anterior region, offers anchorage for a fixed bridge using less invasive surgery compared with bone-augmentation procedures (Ujigawa et al.; Malevez et al., 2004).

Clinically, the response of zygomatic implant, in the long-term, presents good results when prosthetic conditions are correct (Aparicio et al., 2014). However, these results can be failed when the final position of the zygomatic implants is not correct in relation to maxillary sinus and cervical position (RodriguezChessa et al., 2014) that allow sinus pathology, bone resorption, infection and loss of osseointegration. When protocols of installation are correct, the success rate is over than 95\% (Aparicio et al., 2014; Duarte et al., 2007).

Division of Oral and Maxillofacial Surgery, State University of Campinas, Campinas, Brazil.

* Department of Customization, Bioconect Company, São Paulo, Brazil.

*** Department of Prosthesis and Periodontics, State University of Campinas, Campinas, Brazil.

**** Division of Oral and Maxillofacial Surgery, Universidad de La Frontera, Temuco, Chile.

***** Center for Biomedical Research, Universidad Autónoma de Chile, Temuco, Chile. 
The mechanical condition, on the other hand, is an important question in zygomatic implants and the response to this question is not enough. The aim of this study was to investigate mechanical stress in supporting bones around zygomatic implants using photoelastic analysis.

\section{MATERIAL AND METHOD}

Polyurethane Skulls. Were used identical synthetic polyurethane skulls replicas (Nacional, Jaú, São Paulo, Brazil). Synthetic replicas were chosen to eliminate many of the variables associated with human cadaveric skulls and bone from animal sources. From these replicas, was established guidelines to perform the implants obtaining parallelism and similar angulation. Finally, the model skulls were made in photoelastic resin reproducing the angulation of implants obtained in the models of polyurethane.

Dental Implants. The INP System Implants (Sistema de Implantes Nacionais e Próteses) was used. The standard implants were used (Conus ${ }^{\circledR}$ ) with cylindrical body and conical apex, external hexagon $3.5 \times 10 \mathrm{~mm}$. The zygomatic implants were used (JTR®) cylindrical body and external hexagon $4.0 \times 50.0 \mathrm{~mm}$.

Implant Superstructures. To make the prosthetic structure we used metal abutment UCLA type titanium INP System Implants (Sistema de Implantes Nacionais e Próteses) and cylindrical bars pre-fabricated in Ti$6 \mathrm{Al}-4 \mathrm{~V}$ with $3.0 \mathrm{~mm}$ diameter. For the union of the bars we used laser welder (Desktop Laser-Dentaurum Germany), programmed at $365 \mathrm{~V}$, with a focus $9 \mathrm{~ms}$ pulse and frequency set at zero.

The structure was made using laser welding of titanium components prefabricated because in addition to excellent passive and adaptation on the implants and mechanical strength, it is a fast method, low cost and thus also widely used in clinical practice, especially in immediate loading.

Photoelastic Models. Two models performed with different rehabilitation protocols using zygomatic implants were evaluated.

Model 1 - Two zygomatic implants associated with 2 standard implants in the anterior maxilla (Fig. 1).

Model 2 - Two zygomatic implants associated with 4 standard implants in the anterior maxilla (Fig. 2).

For fabrication of the photoelastic skulls it was necessary to manufacture tooling for latter injection of photoelastic resin. From the polyurethane skull models

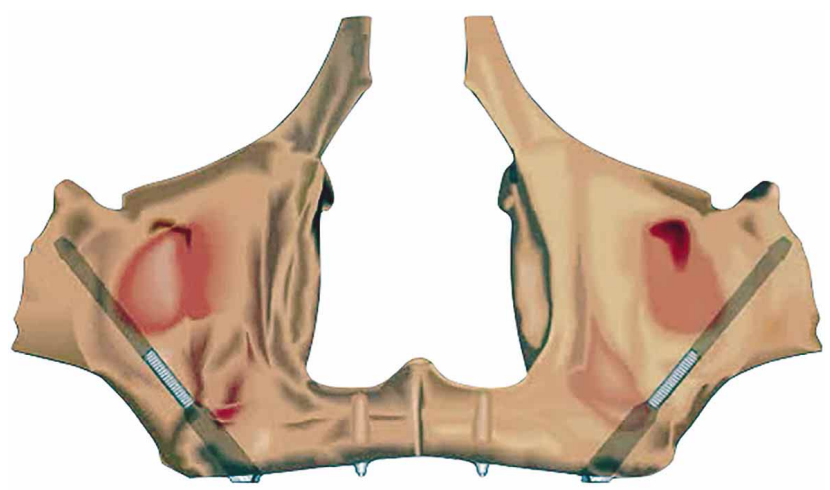

Fig 1. Two zygomatic implants and two standard implants in the anterior area. The zygomatic implant is positioned in the upper first molar area.

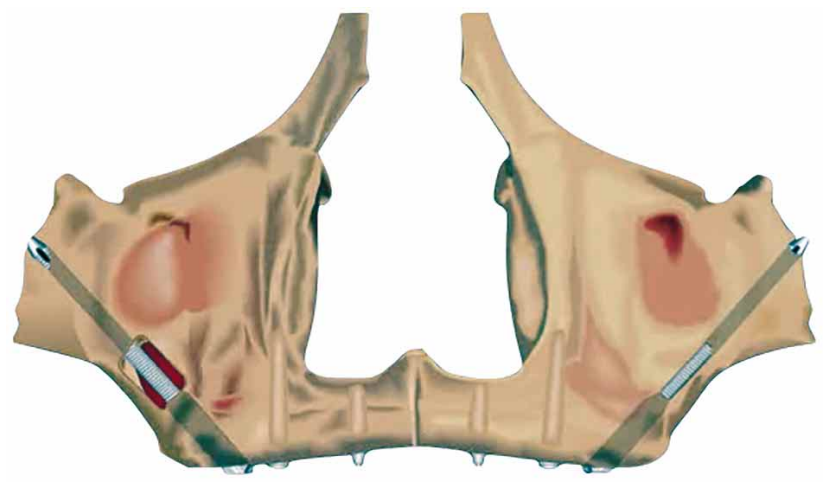

Fig 2. Two zygomatic implants and four standard implants. Zygomatic implants titled is the same than model 1.

with implants already installed, the manufacture of the tooling was made from rigid and external structures lined with a flexible surface, superimposed on the lid and bottom.

Thus, obtaining the components of the flexible resin Polipox $I I 囚, A$ (resin) and $B$ (reagent) these were weighed using a balance of precision with the ratio recommended by the manufacturer, then mixed to become homogeneous and placed in a desiccator attached to a vacuum pump. This process removed all micro-bubbles from the resin and the end of this procedure was performed on resin injection tooling. After the injection, tooling goes through two processes: 1) deposited in a hyperbaric chamber at a pressure of $30 \mathrm{lbs}$ for a period of 12 hours and 2) twenty-four hours drying environment. 
Photoelastic Test. The photoelastic models were taken to a plane polariscope (Eikonal Instrumentos ${ }^{\circledR}$, Ópticos Comércio e Serviço, São Paulo, SP, Brazil) attached to the Instron 4411 test machine and submitted to loading at the first molar region for up to a $2-\mathrm{mm}$ displacement, at a $1-\mathrm{mm} / \mathrm{minute}$ speed. This was the speed that presented the best distribution of isochromatic fringes during the pilot tests for the stress distribution. The photoelastic models were photographed before load input to check for absence of residual stress over the models. They were also filmed and photographed after the desired displacement $(2 \mathrm{~mm})$. For this task, the qualitative method of analysis was applied.

\section{RESULTS}

After the $2 \mathrm{~mm}$ displacement with application of unilateral load on the zygomatic region implant, a photographic record was taken to analyze the stress fringes. It was possible to see that the stress zones were located especially around body and frontal process of zygomatic bone. Also, the cervical area in both models did not show load distribution.

Model 1: The fringes are present in the apical area of the zygomatic implant in the load side; stress distribution is present in the frontal process and infraorbital rim; all zygomatic body is included in the load distribution. The non-load side showed a zygomatic implant without distribution in the zygomatic body with distribution in the infraorbital rim and frontal process. Standard implant showed distribution in the apical area; the piriform area is not involved in stress distribution (Fig. 3).

Model 2: Lesser stress than in model 1 is observed. The zygomatic body in the load side showed less stress than model 1; stress distribution is present in the frontal process with a little distribution in the infraorbital rim. The non-load side with zygomatic implant showed stress distribution close to the apical area, without distribution in the frontal process and zygomatic body. The standard implant showed a minor distribution than model 1 with a poor stress in the apical area (Fig. 4).

\section{DISCUSSION}

Mechanical parameters are excellent indicators of the mechanical risk because they are objective and can be measured.

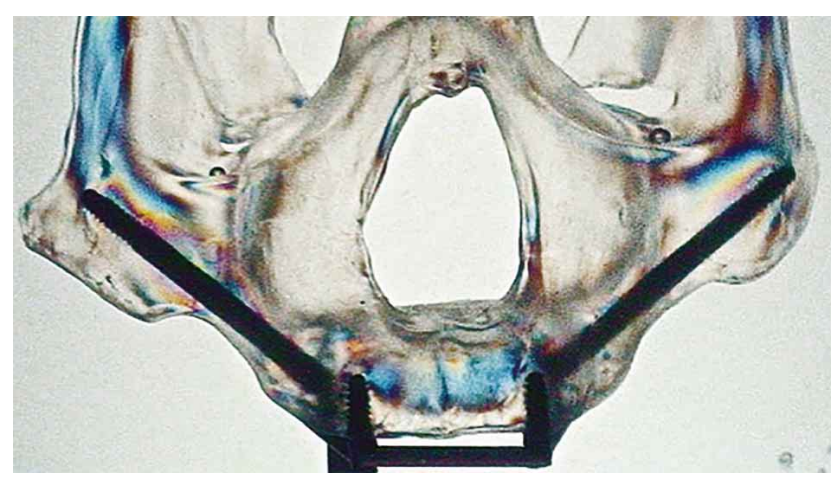

Fig. 3. Model 1 with load in the right side. Stress distribution in the zygomatic bone and frontal process are observed.

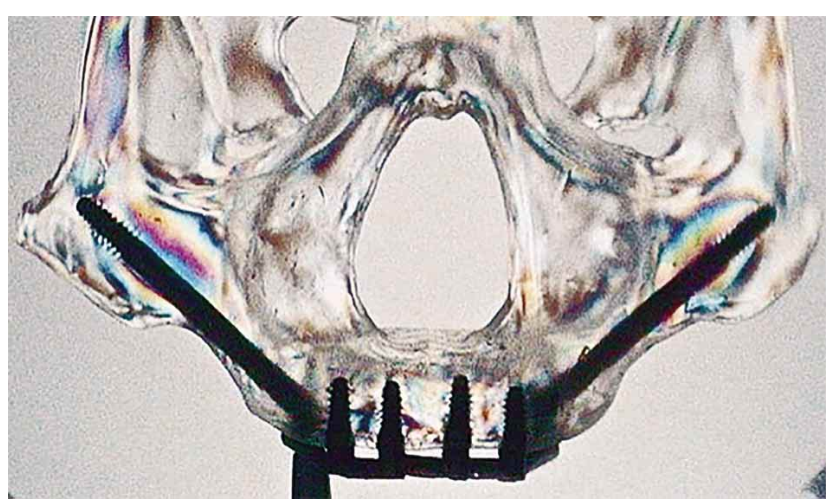

Fig. 4. Model 2 with vertical load in the right side; minor fringes than in model 1 were observed. Low fringes are observed in the standard implants.

The application of loads was carried out in the area corresponding to the first molar. Studies show that higher loads are found in the occlusal region of molar teeth (Ferrario et al., 2004). Importantly, the photoelastic analysis reveals the stress distribution independent of the amount of force applied. The force applied in this test is determined by the mechanical specification of the resin used.

Theoretical models and in vivo measurements found that the bite force varies along the dental arch, being largest corresponding to the posterior teeth (molars and premolars), intermediate in the canine area, and least in an incisal clench (Fernandes et al., 2003; Fontijin-Tekamp et al., 2000; Tortopidis et al., 1998). Thus, this study evaluated the distribution of loads aimed at analyzing the mechanical behavior by means of loads distribution in photoelastic resin skulls simulating the two types of rehabilitation using zygomatic implants. 
Photoelastic analysis has been extensively used in different fields of biomechanics and several reviews dealing with the technique may be found in the literature. Several studies related to implant dentistry have used photoelastic analysis to investigate the effect of implant abutment angulation (Clelland et al., 1993; Ochiai et al., 2003), implant-abutment interface design/retention mechanisms and the performance of implant-tooth supported fixed partial dentures upon load transfer (Ochiai et al.).

Some authors (Parel et al., 2001; Penarrocha et al., 2007) suggest that zygomatic implants offer an especially powerful treatment in prosthetic rehabilitation for edentulous patients with maxillary atrophy, and virtually eliminate the need for bone grafts on the floor of the maxillary sinus. Also, they suggested that zygomatic implants should be installed in combination with at least two standard implants in order to distribute the functional load and to prevent rotational loads (Aparicio et al., 2008). In studies on multiple implants splinted together on a superstructure, no difference was observed in stress on cortical bone between angled and non-angled implants (Zampelis et al., 2007); our result show clear difference in stress distribution, first between the zygomatic implant and second in the standard implants.

The cervical area is not subjected to load in this model and this situation is very important because clinically, this bone is very small and shows a low quality (Branemark et al., 2004). The presence of a zygomatic implant can be result in exclusively load in the apical area and not in the cervical area. Complications in this area are related to sinus pathology, drainage and mucositis (Rodriguez-Chessa et al.); with the absence of the load in this area, some adjunctive procedures can be realized to better condition in the long-time.

On other hand, zygomatic implant position is not unique and show relation with the maxillary sinus. Aparicio (2011) observed that some implants are laterally to the maxillary sinus and others are into the maxillary sinus. In load terms, this position is not relevant because the middle area of the zygomatic implant is not used in the stress distribution.

The photoelastic test suggested that, in Model 1 , all stress is concentrated around the attachment system showing a greater concentration of loads on the body and frontal process of zygomatic bone when compared to Model 2. In addition, the Model 2 had a better distribution of loads in the anterior maxilla. Considering the limitations of the methodology applied, the stress distribution was similar to Ujigawa et al. Regular implants used in the anterior area are very important for stress distribution. However, the response of this implant in the mechanical behavior shows differences when compared with other standard systems, like all on tilted system (de Faria Almeida et al., 2014); with zygomatic implants, the anterior implants show load mainly in the apical area but with standard implants, the load shows distribution in all of the implant.

However, there are limitations to the photoelastic analysis, mainly in biologic simulations that need studies to assume some simplifications. Bone is a complex living structure without a defined pattern; its characteristics vary among individuals Because of individual differences in the morphology of the jaw bone, the results obtained do not apply to all individuals.

Under the conditions tested, both rehabilitation techniques using zygomatic implants were biomechanically efficient. However, the rehabilitation with 2 zygomatics implants and 4 standard implants (Model 2) provided the most favorable behavior.

DE MORAES, P. H.; NÓBILO, M. A.; DE MORAES, M.; OLATE, S. \& ALBERGARIA-BARBOSA, J. R. Análisis fotoelástico de dos protocolos maxilares con uso de implantes cigomáticos. Int. J. Odontostomat., 9(1):107-111, 2015.

RESUMEN: El objetivo de este estudio fue analizar el estrés in vitro y la distribución de tensiones en la estructura craneofacial a partir de los implantes cigomaticos. Réplicas de cráneo de poliuretano fueron usados como modelos para la instalación de implantes cigomáticos estándar utilizando dos modelos de distribución de implantes. Estos modelos fueron usados como modelos utilizando 1 implante en cada lado con dos o cuatro implantes convencionales en la región anterior maxilar (grupo 1 y grupo 2); posteriormente, se realizó una carga compresiva unilateral en la máquina Instrom 4411 utilizando $2 \mathrm{~mm}$ de desplazamiento máximo. La distribución de estrés se concentró principalmente en la región de cuerpo de hueso cigomático y en la región frontal del proceso cigomático; el modelo 1 , con dos implantes convencionales, mostró mayor distribución de estrés en la región cigomática al comparase con el grupo 2; bajo estas condiciones, se concluye que la distribución con cuatro implantes convencionales entrega mejores condiciones de distribución de tensiones.

PALABRAS CLAVE: análisis fotoelástico, atrofia maxilar, implante cigomático. 


\section{REFERENCES}

Aghabeiji, B. \& Bousdras, V. A. Rehabilitation of severe maxillary atrophy with zygomatic implants. Clinical report of four cases. Br. Dent. J., 202(11):669-75, 2007.

Aparicio, C. A proposed classification for zygomatic implant patient based on the zygoma anatomy guided approach (ZAGA): a cross-sectional survey. Eur. J. Oral Implantol., 4(3):269-75, 2011.

Aparicio, C.; Manresa, C.; Francisco, K.; Ouazzani, W.; Claros, P.; Potau, J. M. \& Aparicio, A. The long-term use of zygomatic implants: a 10-year clinical and radiographic report. Clin. Implant. Dent. Relat. Res., 16(3):447-59, 2014.

Aparicio, C.; Ouazzani, W. \& Hatano, N. The use of zygomatic implants for prosthetic rehabilitation of the severely resorbed maxilla. Periodontol. 2000, 47:162-71, 2008.

Branemark, P. I.; Gröndahl, K.; Ohrnell, L. O.; Nilsson, P.; Petruson, B.; Svensson, B.; Engstrand, P. \& Nannmark, U. Zygoma fixture in the management of advanced atrophy of the maxilla: technique and long-term results. Scand. J. Plast. Reconstr. Surg. Hand Surg., 38(2):70-85, 2004.

Clelland, N. L.; Gilat, A.; McGlumphy, E. A. \& Brantley, W. A. A photoelastic and strain gauge analysis of angled abutments for an implant system. Int. J. Oral Maxillofac. Implants, 8(5):5418, 1993.

de Faria Almeida, D. A.; Pellizer, E. P.; Verri, F. R.; Santiago, J. F. Jr. \& de Carvalho, P. S. Influence of tapered and external hexagon connections on bone stresses around tilted dental implants: three-dimensional finite element method with statistical analysis. J. Periodontol., 85(2):261-9, 2014.

Duarte, L. R.; Filho, H. N.; Francischone, C. E.; Peredo, L. G. \& Brånemark, P. I. The establishment of a protocol for the total rehabilitation of atrophic maxillae employing four zygomatic fixtures in an immediate loading system--a 30-month clinical and radiographic follow-up. Clin. Implant Dent. Relat. Res., 9(4):186-96, 2007.

Fernandes, C. P.; Glantz, P. O.; Svensson, S. A. \& Bergmark, A. A novel sensor for bite force determinations. Dent. Mater., 19(2):118-26, 2003.

Ferrario, V. F.; Sforza, C.; Zanotti, G. \& Tartaglia, G. M. Maximal bite forces in healthy young adults as predicted by surface electromyography. J. Dent., 32(6):451-7, 2004.

Fontijn-Tekamp, F. A.; Slagter, A. P.; Van Der Bilt, A.; Van'T Hof, M. A.; Witter, D. J.; Kalk, W. \& Jansen, J. A. Biting and chewing in overdentures, full dentures, and natural dentitions. J. Dent. Res., 79(7):1519-24, 2000.

Malevez, C.; Abarca, M.; Durdu, F. \& Daelemans, P. Clinical outcome of 103 consecutive zygomatic implants: a 6-48 months follow-up study. Clin. Oral Implants Res., 15(1):18-22, 2004.
Ochiai, K. T.; Ozawa, S.; Caputo, A. A. \& Nishimura, R. D. Photoelastic stress analysis of implant-tooth connected prostheses with segmented and nonsegmented abutments. $J$. Prosthet. Dent., 89(5):495-502, 2003.

Parel, S. M.; Brånemark, P. I.; Ohrnell, L. O. \& Svensson, B. Remote implant anchorage for the rehabilitation of maxillary defects. $J$. Prosthet. Dent., 86(4):377-81, 2001.

Peñarrocha, M.; García, B.; Martí, E. \& Boronat, A. Rehabilitation of severely atrophic maxillae with fixed implant-supported prostheses using zygomatic implants placed using the sinus slot technique: clinical report on a series of 21 patients. Int. J. Oral Maxillofac. Implants, 22(4):645-50, 2007.

Rodríguez-Chessa, J. G.; Olate, S.; Netto, H. D.; Shibli, J.; de Moraes, M. \& Mazzonetto, R. Treatment of atrophic maxilla with zygomatic implants in 29 consecutives patients. Int. J. Clin. Exp. Med., 7(2):426-30, 2014.

Tortopidis, D.; Lyons, M. F.; Baxendale, R. H. \& Gilmour, W. H. The variability of bite force measurement between sessions, in different positions within the dental arch. J. Oral Rehabil., 25(9):681-6, 1998.

Ujigawa, K.; Kato, Y.; Kizu, Y.; Tonogi, M. \& Yamane, G. Y. Threedimensional finite elemental analysis of zygomatic implants in craniofacial structures. Int. J. Oral Maxillofac. Surg., 36(7):6205, 2007.

Zampelis, A.; Rangert, B. \& Heijl, L. Tilting of splinted implants for improved prosthodontic support: a two-dimensional finite element analysis. J. Prosthet. Dent., 97(6 Suppl.):S35-43, 2007.

Correspondence to:

Prof. Dr. Sergio Olate

Division of Oral and Maxillofacial Surgery

Claro Solar 115, oficina 414-A

Temuco

CHILE

Email: sergio.olate@ufrontera.cl

Received: 15-10-2014

Accepted: 23-01-2015 